Send your letters to the Editor,

British Dental Journal,

64 Wimpole Street

London

W1G 8YS

E-mail bdj@bda.org

Priority will be given to letters less than 500 words long.

Authors must sign the letter, which

may be edited for reasons of space.
Editor-in-Chief's note: Both the following letter and response are far longer than we would normally publish, however, we are making an exception in this case in view of the importance of the subject. Subsequent responses must adhere to the usual ruling of being under 500 words.

\section{CONSCIOUS SEDATION}

Sir, the paper ${ }^{1}$ by Drs Mikhael, Wray and Robb which describes a technique of intravenous conscious sedation using a combination of midazolam, alfentanil and ketamine raises some issues which we feel require further explanation.

First, at the time the study was carried out, all published Standards and Guidelines advised ${ }^{2}$ that intravenous conscious sedation in children ought to be a rare event and recommended that it should be used only after all other options had been exhausted and then, preferably in a hospital setting. Second, the use of any of these drugs for conscious sedation in children was (the position has since changed for midazolam) outwith the product licence and we know of no peer reviewed data regarding the pharmacological consequences of their use in combination. Given these two points, we must assume that the information presented in the paper was gathered using a research protocol. If so, was ethical approval sought, and from whom? Did the parents give fully informed consent both for the research and for the use of the unapproved drugs? Were they told about the unpredictable risk of deep sedation (deemed to be equivalent to general anaesthesia by the GDC and therefore unacceptable outside a hospital setting)?

Third, Dr Mikhael presented a paper ${ }^{3}$ relating to 6,000 children sedated as described above to The Dental Sedation Teachers Group (DSTG) in 2005. Were these the same patients as in the 2007 paper $^{1}$ and if so, what part, if any, did Drs Wray and Robb play in the earlier single author study? ${ }^{3}$

Our fourth concern relates to the way in which the drugs were administered. Conscious sedation is a state, not a defined entity, and varies from patient to patient. Indeed, the state may vary in the same patient on different treatment occasions. Thus it is not possible to define a specific dose of an intravenous sedative drug. Therefore, all standards and guidelines advocate titration of a single drug to be certain that the state of conscious sedation does not progress to deep sedation or general anaesthesia. However the studies ${ }^{1,3}$ described here relate to three drugs, with a wide range of dosage. When such a mixture of drugs is used how does one determine dosage? In what order and to what end point are the individual drugs given? In addition, there is some confusion in the article by Dr Mikhael ${ }^{3}$ over titration versus bolus intravenous injections, and potency versus length of action of the drugs used. Onset time of the drugs is not mentioned. Although having eschewed titration as 'theoretically illogical', because of this confusion the earlier article concludes that 'titration of midazolam alone or the entire mixture gives an added safety margin against the tendency towards deep sedation'.

The first requirement of any technique of conscious sedation is that there should be a sufficient margin of safety. Although the incidence of both was less that 1\%, Mikhael, Wray and Robb reported $^{1}$ that there were occasions when verbal responsiveness was lost or oxygen saturation decreased below acceptable levels. Those episodes may have had no consequences, but suggest to us that the technique does not have a sufficient margin of safety for the general dental practice setting. We are aware of at least four cases where a multi-drug intravenous technique (given outside a hospital setting) has been associated with significant patient morbidity and view the use of such methods in outpatient dentistry with some concern. Central nervous system depressants act synergistically, a fact which the authors acknowledge, in regard to increased efficacy at low doses. This will also reduce the incidence of unwanted effects specific to each agent, but the potential for cardio-respiratory depression is common to each, and these effects will also be increased synergistically.

Our comments do not mean that we deny that some patients are resistant to the traditional techniques of sedation or that we would wish to obstruct the evaluation of new methods. ${ }^{4}$ However, these must be evaluated in properly designed, formally established research protocols. Crucially, the technique must be defined exactly so that others can try and assess it. The simple statement of the dose range for three very different drugs is insufficient in this regard.

\section{Strunin, London,}

T. Wildsmith, Dundee

1. Mikhael M S, Wray S, Robb N D. Intravenous conscious sedation in children for outpatient dentistry. Br Dent J 2007; 203: 323-331.

2. Strunin L. Conscious sedation for dental treatment: am I my brother's keeper? Anaesthesia 2007: 62: 645-647.

3. Mikhael M. Conscious sedation in children; a review of 6000 cases. Dental Sedation Teachers Group (DSTG) autumn 2005; 5: 5.

4. The General Dental Council. Maintaining standards: guidance to dentists on professional and personal conduct. November 1998 with amendments up to November 2001. 
The authors respond: Thank you for giving us the opportunity to reply to Professors Strunin and Wildsmith's letter concerning our publication.

Firstly we would like to point out that at the time that the initial 1,000 patients were treated (January 2000 - September 2001) general anaesthesia for dentistry was still available in general dental practice. Indeed these patients were all treated within facilities that provided general anaesthesia for dentistry at that time. Thus had any patient become deeply sedated there would have been no problem with their management in that setting.

Regarding the issue of consent, all the parents of the patients gave consent to the administration of intravenous conscious sedation. The authors are unaware of any requirement to specify any further details.

Ethical committee approval was not required as the sedation technique was already in use in the practice prior to the decision to audit the technique. The study involved collecting data on patients without altering the treatment they received.

The professors are correct that the General Dental Council's (GDC's) guidancel $^{1}$ equated the state of 'deep sedation' with general anaesthesia in terms of the facilities required for treatment. They are totally incorrect to state that it would not be acceptable outside the hospital setting, as this restriction did not come into force until 31 December 2001 in England. ${ }^{2}$ We are at a loss to know which guidance Professors Strunin and Wildsmith are referring to in the first paragraph of their letter as the reference relates to an editorial Professor Strunin has published last year. ${ }^{3}$ In that he quotes many documents and reports some of which predate and many of which postdate this audit. It would be much easier to answer the point if it would be clearly stated which document they are quoting. We know of no guidance as of that period which would support the statements.

Professor Strunin describes an 'unpredictable risk of deep sedation' in his paper. Loss of verbal contact is a recognised complication of conscious sedation. All those who administer conscious sedation are trained to manage this complication, as is described in the Dental Sedation Teachers' Group publications. ${ }^{4-7}$ In this audit the incidence of loss of verbal contact was 6 in 1,000 (0.6\%). Anyone with any statistical knowledge must accept that a $0.6 \%$ chance is unlikely! This also compares favourably with other audits of sedation in dentistry, ${ }^{8}$ although data are somewhat sparse, and particularly well with a paper published by Professor Strunin in $1979^{9}$ where he recommended the use of multiple agent intravenous sedation despite the high complication rate (two cases of respiratory obstruction and two of respiratory arrest - out of 49 patients (8\% some 13 times higher than in the present study)).

We know that many anaesthetists who have used ketamine, alfentanil and midazolam in the course of general anaesthesia appear to assume that this combination of drugs would always cause unconsciousness. This is only true in the doses designed to produce that effect. However, if these drugs are given in sub-anaesthetic doses, particularly when carefully titrated, their effect is exactly as described in our article. Children are conscious as desired and we are able to communicate with them throughout the procedure with 'a wide safety margin rendering loss of consciousness unlikely.'

It is therefore imperative to observe this technique in order to be able to provide a valid opinion.

We have in the past invited sceptical parties to observe this technique over a whole day with an average of 15 children sedated and all were satisfied that the technique is safe and credible in addition to being compliant with the current regulations issued by the $S D A C^{10}$ and supported by the GDC. ${ }^{11}$ We have also demonstrated the technique to two past presidents of the Association of Dental Anaesthetists to provide them with substantiation when judging similar techniques.

We must highlight, however, that we share professor Strunin's ${ }^{3}$ as well as other publications ${ }^{\prime 2}$ concerns regarding a minority of dentists or anaesthetists, who, in the isolated setting of a dental practice, through lack of training or experience or both could make the use of any sedation technique potentially disastrous if also coupled with poor resuscitation training.
With this in mind we also must stress other areas that require scrutiny.

The first is that several combinations of sedative drugs are used widely at a national level. They are used in various practices for the purpose of providing a sedation service both to adults and children. The vast majority conform to current GDC regulations and are administered by responsible, experienced sedationists. Nonetheless a small minority break the rules and provide disguised general anaesthesia with potentially harmful outcomes. We therefore back recommendations made by Dr P. Coulthard ${ }^{13}$ as well as Professor Wildsmith and $\mathrm{Dr}$ Craig's $^{14}$ in the necessity to create some regulatory bodies to oversee the clinics in providing the service.

Since Professor Strunin's early publication in Anaesthesia in 1979, ${ }^{9}$ enormous progress was made in the provision of sedation with newer drugs introduced and monitoring equipment refined that would make multiple drug sedation a much safer formula and the inadvertent unconsciousness much less likely.

Another point is that The Standing Dental Advisory Committee report to the Department of Health, which is supported by the GDC, states that 'the effective management of pain and anxiety is of paramount importance for patients requiring dental care and conscious sedation is a fundamental component of this and competently provided conscious sedation is safe, valuable and effective.' ${ }^{10}$

We therefore do not agree that the purpose of conscious sedation is 'limited to encouraging the patient to accept the local anaesthetic'. It is right that these individuals have access to appropriate methods of pain and anxiety control. ${ }^{15}$

The GDC has indicated in its previous guidance that this is both a right for the patient and a duty placed on the dentist. ${ }^{1}$

In response to other points raised in the Professors Strunin and Wildsmith letter and as mentioned in the publication:

*We were not sure what they meant by a mixture of drugs in 'approved use'. We are not aware that manufacturers have the power or the knowledge to provide this reassurance. In anaesthesia where every patient receiving a general anaesthetic is given a large number of drugs, 
each produces a specific effect. Their compatibility is the responsibility of the administering physician.

${ }^{* *}$ As to the patients presented to the 'Dental Sedation Teachers Group' these were the same cases but the audit was not fully completed at the time of presentation and only principles were discussed with no particulars. The purpose of the presentation was to compare experiences. Had either correspondent attended the meeting they would have a better understanding of what was presented and the reasons for the presentation.

${ }^{* * *}$ As to the issue of titration, although clearly described in our publication, it is worth a clarification. As the audit took a long time to complete, the technique underwent modifications to reduce to a minimum the possibility of inadvertent unconsciousness.

As titration was then well emphasised in SAAD's publications, the titration of one drug initially (midazolam) had been undertaken as a routine. As time passed and further data were collected Dr Mikhael then found that, although illogical, titration of the whole mixture worked best.

We must also mention at this point that several very similar techniques involving multiple drug sedation in children were presented in a variety of meetings of $S A A D$ as well as the Association of Dental Anaesthetists over the past few years.

Two important publications have recently been produced. These are firstly the joint publication from the RCS (Eng) and RCA in October 2007 and secondly from the Department of Health in January 2008 listing the use of combinations of intravenous sedatives as 'alternative techniques' in conscious sedation, rightly emphasising standards of training and experience desired in administering sedationists. ${ }^{16,17}$

The dental profession and those working with them to provide appropriate pain and anxiety control are committed to provide high quality patient care. As part of that process it is incumbent on us to audit our activity. Wherever possible our experiences should be shared - hence the presentations at meetings and the articles in peer refereed journals.

1. General Dental Council. Maintaining standards Guidance to dentists on professional and personal conduct. London November 1998 and amendments to November 2001.

2. A conscious decision. A review of the use of general anaesthesia and conscious sedation in primary dental care. Report by a Group chaired by the Chief Medical Officer and Chief Dental Officer. London: Department of Health, 2000.

3. Strunin L. Conscious sedation for dental treatment. Am I my brother's keeper? Anaesthesia 2007; 62:645-647.

4. Sedation in dentistry: undergraduate training. Guidelines for Teachers. Dental Sedation Teachers' Group, 1999.

5. Sedation in dentistry: the competent graduate. Dental Sedation Teachers' Group, 2000.

6. Training for safe practice in advanced sedation techniques for adult patients. Dental Sedation Teachers' Group, 2003.

7. Training in conscious sedation for dentistry. Dental Sedation Teachers' Group, 2005.

8. Robb ND, Bendkowski A. Paediatric intravenous conscious sedation - an audit of current practice. CPD Dentistry 2003; 4: 1-24.

9. Coral I M, Strunin L, Ward M E, Mason SA, Alcalay $M$. Sedation for outpatient conservative dentistry. A trial of pentazocine supplementation to diazepam and local analgesia techniques. Anaesthesia $1979 ; 34: 855-858$

10. Conscious Sedation in the Provision of Dental Care Report of an Expert Group on Sedation for Dentistry. The Standing Dental Advisory Committee. London: Department of Health, 2003.

11. Standards for Dental Professionals. London: General Dental Council, 2005.

12. Dental Sedation Teachers Group. Training for safe practice in advanced sedation techniques for adult patients. A discussion paper. London, DSTG, 2003.

13. Coulthard P. Sedation for dental treatment. Anaesthesia 2007; 62: 1184-1185.

14. Wildsmith A, Craig D. Br J Anaesth 2008; January review supplement.

15. A Standing Dental Advisory Committee Report for the Department of Health. Conscious Sedation in the provision of Dental Care. Report of an Expert Group in Sedation for Dentistry. London: Department of Health, 2003.

16. Standards for Conscious Sedation in Dentistry: Alternative Techniques. A Report from the Standing Committee on Sedation for Dentistry. FDSRCSEng, 2007.

17. Guidelines for the Appointment of Dentists with a Special Interest (DwSI) in Conscious Sedation. Department of Health/Faculty of General Dental Practice (UK), 2008.

DOI: 10.1038/sj.bdj.2008.415

\section{GREAT ENDEAVOUR}

Sir, as a graduate from the University of Aberdeen Medical School I am delighted to see a dental school opening there. I myself am very keen on a career in oral and maxillofacial surgery and in the not too distant future hope to return to dental school. The North East of Scotland is in desperate need of a dental institute and a facility to train dental surgeons who are committed to treating patients in the region. I hope that this new venture stimulates an excitement among oral health academic staff with interests in research and teaching. Aberdeen University Forresterhill campus has some cutting edge research facilities in the form of the Institute of Medical Science, and also the new Matthew Hay teaching and learning centre.

What is of interest to your readers is that in 1946 The Final Report of the InterDepartmental Committee on Dentistry, ${ }^{1}$ or the Teviot Report, was published. This report commented on, among other things, the provision of dental services in the North East of Scotland and suggested that the University of Aberdeen should consider the opening of a dental school. ${ }^{2,3}$

This is of relative interest to me, as my great grandfather, Thomas Rankin OBE QHDS FDS (1884-1959) was on this committee. Tom Rankin was a consulting dental surgeon at the Ballochmyle and Bangour Plastic Surgery and Jaw Injury Unit during the Second World War. He was also the first lecturer in maxillofacial injuries at Glasgow Dental Hospital and School.

The creation of this new dental school in an already established university with a strong record in biomedical research and medical education is a great thing which I hope is fully utilised by patients, researchers and educationalists. I also hope that the dental school looks into the various services it can offer to the North East of Scotland. I hope that the university and the Scottish Parliament seek out appropriate experts in their fields for this new endeavour.

T. W. M. Walker Ireland

1. Final Report of The Inter Departmental Committee on Dentistry. HSMO, February 1946.

2. McF R, TH J D. Obituary: Thomas Rankin. Br Dent J 1959; 106: 290-291.

3. Boyes J. Appreciation: Thomas Rankin. Br Dent J 1959; 106: 381

DOI: $10.1038 /$ sj.bdj.2008.416

\section{INTO THE FIRE}

Sir, I write in reference to http:// www.nice.org.uk/nicemedia/pdf/ CG64PIEQRG.pdf. Looks simple: we don't need to prescribe for patients at risk of bacterial endocarditis.

Look again: for all patients at risk of bacterial endocarditis it appears dentists are expected to:

1. Discuss the risks and benefits of antibiotic prophylaxis

2. Explain why antibiotic prophylaxis is no longer routinely provided

3. Explain the benefits of maintaining 
good oral health (+? the risks of bacteraemia which attach to it also)

4. Inform patients of the symptoms of infective endocarditis and the action they should take

5. Investigate and promptly treat all dental bacterial infections which pose a potential risk to the patient:

a. acute and chronic non-periodontal infections

b. presumably close and ongoing management of relevant periodontal disease.

Assuming the above interpretation is correct, then I believe that:

A. Cardiologists and other relevant cardiac condition diagnosing clinicians should:

i. fully inform patients in relation to points 1, 2, 3, and 4 above at the time of diagnosis

ii. refer all patients for a dental examination at the time of diagnosis

iii. provide a full description of the cardiac condition to the patient, attach any recommendations, advise the patient to provide that information to all dentists they visit and also copy the information to the patient's current dental health care providers

B. Dentists should have access to a rapid action second tier support service for at risk patients (microbiological service in particular)

C. Dentists should have access to a counselling referral service which can provide any additional specialist level medical information which a patient may seek

D. Defence bodies in conjunction with other stakeholder bodies should prepare a proforma detailed dedicated medical history and advice sheet for at risk patients.

$$
\begin{array}{r}
\text { P. Mc Crory } \\
\text { Bury }
\end{array}
$$

DOI: 10.1038/sj.bdj.2008.417

\section{TURNED ON ITS HEAD}

Sir, I would like to thank the authors of NICE clinical guideline 64 'Prophylaxis against infective endocarditis', for clearly stating that 'antibiotic prophylaxis against infective endocarditis is not recommended for people undergoing dental procedures'. ${ }^{1}$ Whilst the wholesale ending of antibiotic prophylaxis for dental procedures, regardless of perceived risk of IE, will prove controversial in some circles, the detailed analyses of the evidence in the document shows no convincing evidence of benefit to patients, and that there are real risks from anaphylaxis and antimicrobial resistance. Hopefully the profession will take this guidance on board, and begin the difficult process of educating our patients and medical colleagues as to why 50 years of dogma has been turned on its head.

\section{A. Keightley} Glasgow

1. NICE clinical guideline 64 'Prophylaxis against infective endocarditis - Antimicrobial prophylaxis against infective endocarditis in adults and children undergoing interventional procedures' March 2008.

DOI: $10.1038 /$ sj.bdj.2008.418

\section{CARCINOGENIC ASBESTOS}

Sir, I noted with interest the letter on asbestos dressings from A. Cook (BDJ 2008; 204: 224).

When I was a houseman at The London Hospital in 1966, I mixed some gingivectomy pack for a patient. He asked me what was in the dressing, and when I told him it contained asbestos he ran hastily out of the clinic! The patient later told me he worked in the Department of Pathology and knew asbestos to be highly carcinogenic, especially on inhalation.

This fact intrigued me so much that I looked into the probable dangers of asbestos, and published an article the following year in the $B D J .^{1}$ I understood that following the publication of this article, the use of asbestos-containing packs ceased almost immediately in dental schools throughout the UK.

M. Yewe-Dyer

Alton

1. Dyer M R Y. The possible adverse effects of asbestos in gingivectomy packs. Br Dent J 1967; 120: 507. DOI: 10.1038/sj.bdj.2008.419

\section{CASE STUDY POLICY}

Sir, with the pressure on publication space and the fierce competition to get published, journals now frequently reject single case studies through their peer review process.
Although these case studies do not always add new information to the literature I believe that they do add up to a data pool. Also, by reviewing the literature on PubMed, a false impression of the incidence, prevalence, predilection or other factors may be gained.

I suggest that all journals establish a separate section called 'Case documentation' or 'Case database' for publishing such cases, in order to allow accumulation of documented data. To maintain quality, criteria should be established such as the inclusion of complete history, investigation reports with photographs, radiographs and other imaging techniques employed, pathology report, treatment provided and follow up details.

$$
\begin{array}{r}
\text { K. A. Bishen } \\
\text { Mangalore } \\
\text { DOI: } 10.1038 / \text { sj.bdj.2008.420 }
\end{array}
$$

\section{DOING JUSTICE TO PAIN}

Sir, it is good to see an update on pain, a much neglected topic at least in my education. But it is disappointing to see that the approach is as one sided as it was 40 years ago. There is a whole landscape of information about pain from the social sciences which is scarcely mentioned in this update.

More than ten years ago Dworkin and others wrote of the importance of recognising the essential participation of the mind in pain perception. We cannot begin to understand or deal with pain without bringing together both the body and mind. Dworkin helps us here with a practical guide to the diagnosis of TMD pain. The Diagnostic Criteria allow the physical aspects (Axis I) to be separately assessed from the psycho-social (Axis II) so that management can be appropriately directed to each component. The use of a simple questionnaire such as the Hospital Anxiety and Depression score can help the practitioner, untrained in psychology (but deeply perceptive by experience), to flag up the existence of Axis II factors. It is useful to be able to convince the patient that help is needed on both the physical and psychological front, without at any time suggesting that their pain is 'just' psychological.

Professor Renton (BDJ 2008; 204: 335338) makes treating TMD sound fairly straightforward. It does not come that 
easily to me. But when the physical stuff does not work, and a 'diagnosis' of neuralgia is an empty offer, there is much that can be done in a supportive way for patients with chronic pain. Not least is in helping them regain control of their life. An update on these methods would have been helpful. Pain is a complex subject and it is difficult to do it justice.

R. Wilding

Devon

DOI: $10.1038 /$ sj.bdj.2008.421

\section{NON-VITAL PULP}

Sir, I read with great interest the letter to editor entitled Unusual tic by M. E. Green (BDJ 2008; 204: 224). I had a case in which tooth 23 was non-vital and affected the left eye of the patient, who complained that she could not see some of the words while reading sentences. This condition was named as uveitis for which there are various aetiological factors such as toxoplasmosis, acute retinal necrosis, trauma, post surgical bacterial infection, white dot syndrome, juvenile rheumatoid arthritis, tuberculosis, intraocular lymphoma, sarcoidosis and multi-focal choroiditis. All these factors were ruled out, with dental pathology being the confirmed factor in this case despite a nonvital pulp being a very rare cause. Once the root canal treatment of the 23 was completed the clinical signs and symptoms of the patient's eye cleared. Even though the clinical signs and symptoms of the case mentioned by M. E. Green are not similar to my case, the aetiology in both cases is similar - being the non-vital pulp. Hence ophthalmologists should always consider dental pathology as one of the contributing factors for eye problems.

N. V. Ballal

Karnataka

DOI: $10.1038 /$ sj.bdj.2008.422

\section{AIRING COMPLAINTS}

Sir, Junior Doctor F. Speirs' letter (Informed consent; BDJ 2008; 204: 352) may serve as a useful reminder about informed consent. However, the importance of this is as well established in the dental profession as it is in the medical profession. It is taught at all levels from undergraduate to postgraduate diplomas. The letter gives the impression that this is something unique to the medical profession that should be condescendingly passed on to dentists. In fact the letter is simply a complaint about one or possibly two dentists who have treated Dr Speirs. I am not aware of any dentists who have aired their complaints about the undoubted deficiencies of certain members of the medical profession in the pages of the British Medical Journal.

A. Shelley

Manchester

DOI: 10.1038/sj.bdj.2008.423

\section{MUSLIMS AND GOLD}

Sir, I recently had a Muslim patient who was reluctant to wear an acrylic tooth, questioning whether it contained gold, since he stated that Muslim men are prohibited from having gold on them. ${ }^{1}$ Many dental materials such as implants, metal crowns, ceramics or even amalgam may contain certain amounts of gold. Consequently, the discerning clinician should be aware of this and prompt a male Muslim patient to make an informed choice about a proposed treatment option.

\section{T. Sebastian} Tripoli

1. Darwish S. The management of the Muslim dental patient. Br Dent J 2005; 199: 503-504.

DOI: 10.1038/sj.bdj.2008.424

\section{HONOURABLE RETIREMENT}

Sir, when I took a career break from dentistry for health reasons I reluctantly relinquished my registration with the GDC as I felt the fee just to remain on the register as a retired member was just too much.

When I later enquired what my position was to rejoin the register I was told that I was 'removed for non-payment of fees', although I had advised the GDC that I would be retiring before stopping my direct debit payment. What is more my new registration certificate is now a 'Restoration certificate'.

The inference is that I have been removed from the register for default of my fee payment or some other misdemeanour, whereas that is not the case. There is no mechanism to retire from the GDC honourably and with an indication of a respectable career in our profession.

N. Entwistle By email DOI: $10.1038 /$ sj.bdj.2008.425 